\title{
Elaboration of Social Media Performance Measures: From the Perspective of Social Media Discontinuance Behavior
}

\author{
Inwon Kang, Yiya Zhang and Sungjoon Yoo* \\ Department of International Business \& Trade, Kyung Hee University, 26 Kyungheedae-ro, Dongdaemun-gu, \\ Seoul 130-701, Korea; Iwkang@khu.ac.kr (I.K.); zoeyzhang9617@gmail.com (Y.Z.) \\ * Correspondence: sungjoon@daejin1999.com; Tel.: +(0082)-031-273-6634
}

Received: 8 August 2020; Accepted: 21 September 2020; Published: 25 September 2020

check for updates

\begin{abstract}
Social media platforms insist on the so-called "number of visits, clicking, and subscription" as a measurement of social media performance. However, this method of measurement does not take into account dormant user accounts and unintentional clicks or visits. To fully understand social media performance, this study aims to examine the process of users' discontinuance behavior from the view of technostress creators and socialstress creators through social media fatigue. Also, this study investigates the influence of involvement between social media fatigue and discontinuance behaviors. To understand the impact of technostress and social stress creators on users' discontinuance behavior, this study conducted an off- and online survey in Korea. Using Confirmatory factory analysis (CFA), this study has a strong academic contribution because it identifies the existing methods measuring social media performance through numbers of accounts or joining in as inaccurate.
\end{abstract}

Keywords: social media platforms; online performance; social media fatigue; social media involvement; discontinuance behavior

\section{Introduction}

Facebook stated that, as of November 2019, its users in the United States reached 232.6 million [1]. In South Korea, Naver announced that around 14.1 million Koreans joined Naver Band in 2018 [2]. Naver band is a mobile application that facilitates group communication. Users can create separate spaces to communicate with members of different groups. Social media platforms in recent years tend to overstate their social media quantitative efficiency such as membership and clicks as a comprehensive view of social media performance. Many marketing researchers also studied social media performance by focusing on a range of social media usages such as number of accounts, subscribers, registrations, visits, and joining of a social media platform (joining-in) [3-5].

However, performance recognized by platforms in this way might not reflect the actual use of social media because dormant accounts or unintentional visits or clicks inflate social media statistics. A survey report revealed that, in the last year, $42 \%$ of Facebook's users said that they took a break for a period of one week or more and $26 \%$ said that they deleted this app from their cell phone [6].

In this regard, it is inevitable that inactive users, who are not participating in logging in actively, are trying to reduce their use, or leave their accounts dormant, are easily ignored and included to exaggerate social media performance. Therefore, a comprehensive examination of social media performance is necessary.

Since there is little previous research that examined why users quit using social media $[7,8]$ or that focused on users' inactivity and reduced participation, this study aims to be an inclusive examination not only of users' avoidance of social media but also of their reduction in platform usage. That is, 
in addition to the users who quit using social media, dormant and inactive users are also of great significance and should be considered as losses for social media performance. The key question is as follows: Why are dormant and inactive users so important to social media performance? In order to answer this question, it is necessary to find the reason for users' inactivity or abandonment of their accounts. Following this line of thought, when users feel overwhelmed, tired, or dissatisfied, they may try to reduce their usage of or may even close their social media.

Previous research dealing with determinants that induce user fatigue and inactive performance largely focused on technostress, which involves techno overload, information overload, techno complexity, invasion concerns such as invasion of privacy or work, and so on $[8,9]$.

As social media provides services for users which allow them to reveal information about interpersonal relationships and to facilitate social connection, it helps users to disclose not only their personal information but also thoughts and feelings in emotional text. In addition, individuals also aim to be integrated with others by using social media. Users feel satisfied if they share details of their lives with others but become anxious when they have no idea what their friends are up to on social media, which might result in individuals needing to repeatedly check their Social Network Service (SNS) platforms, thus triggering discontinuance behavior [10].

Therefore, excessive social media usage for emotional satisfaction or maintenance of social connections can result in users' social anxiety and reduction in social media usage $[10,11]$. Thus, in order to determine the causes of dormant social media accounts, users' emotional needs and their anxiety about missing out when separated from their main group must be considered.

More importantly, even if users feel exhausted while using social media, strong links to social media, such as keeping in touch with friends or sharing online information, weaken their intention to reduce usage or to quit [12]. Focusing on the connection between users and social media is a significant issue because, if users leave social media, they give up these online connections.

Users' connection with social media has been widely explored by researchers regarding social media addiction but are rarely explored regarding social media discontinuance. Thus, the degree of individuals' connection with social media is another important mechanism to examine regarding social media performance in this study.

In summation, this study seeks to explore the factors that induce social media breaks by considering social media fatigue and its determinants. As such, the results show that social media fatigue has a positive influence on user's discontinuance behavior. Also, in order to elaborate social media performance measurement, this study uses "oblivion" in the analysis to measure dormant users' discontinuance behavior. Lastly, the study points out that high social media involvement weakens users' oblivion and opt out behaviors. This study provides policy suggestions for social media providers in examining social media performance more precisely.

\section{Theoretical Background}

\subsection{Quantifying Social Media Contributions: The Genuine Performance Measure}

In recent years, with the development of social media, measuring social media performance has attracted many scholars. Prior research measuring social media performance mainly addressed quantitative contributions from social media in various ways.

According to innovation diffusion theory, the performance of social media is about how users accept social media as it evolves as a new technology tool [12]. Thus, most prior research has considered social media performance in terms of the number of accounts, subscribers, and websites visited [3]. In addition, as contributions to social media, users' active participation can be expressed from three aspects: likes, comments, and shares. Table 1 shows the quantified contributions of social media platforms' performances, as evaluated in previous research. 
Table 1. Relevant study for social media contribution measures.

\begin{tabular}{ccc}
\hline Researchers & Social Media Quantified Contributions & Social Media Forms \\
\hline$[13]$ & number of visits, comment frequency & Social Networking (Facebook, Myspace) \\
\hline$[14]$ & number of tags, number of additional taggers & Social Tagging (StumbleUpon) \\
\hline$[15]$ & number of views of videos, number subscribers & Media Sharing (YouTube, Flickr) \\
\hline$[16]$ & number of members, number of return visit & Blogs (Blogspot) \\
\hline$[17]$ & number of retweets, number of “likes” & Microblogging (Twitter) \\
\hline$[18]$ & numbers of visitors, number of active users & Wikis (Wikipedia) \\
\hline$[19]$ & number of web clicks & Search engine (Google Search) \\
\hline$[3]$ & number of retweets, number of active users & Social Networking (Facebook)
\end{tabular}

Based on these studies on social media's quantitative contributions, which are overall recognized as social media performance, many studies also investigated a variety of measuring methods. The authors in [20] created a measuring tool called the "social media index," which not only includes Google links, technology ranking, post frequency, numbers of comments, Facebook links, Twitter friends, and blog popularity but also considers social media activities that users perform on other social media platforms, to measure social media performance from a comprehensive perspective. The authors of [21] suggested a social business model to measure social media performance that includes WC, which refers to the number of clicks through content on social media and comprises additional actions such as following an account, expanding an advertisement, favoriting an account, retweeting, or replying.

Other researchers have disagreed that the quantitative contributions mentioned above could be considered social media performance and could be measured by calculated tools or methods. The authors of [9] focused on examining users leaving or switching to other platforms and tried to determine what caused this kind of social media discontinuance behavior. The findings of [9] expanded our understanding of social media performance and provided a more comprehensive view of social media performance measure.

Therefore, due to the debate over whether quantified contributions should be considered the genuine performance of social media or whether the present measuring methods can be used to determine the actual performance of social media must also be considered.

Moreover, in addition to users who stopped using social media, dormant accounts include users who constantly reduce social media use and gradually participate less on social media platforms. Dormant accounts also apply to those users who have either forgotten their social media account username or password. As such, these users might be inactive for a long period on social media. However, as soon as they get hold of their username or password, they can be active again. As of July 2019 , around $40 \%$ of Instagram users in the United States were inactive or middle users [2]. Therefore, when identifying and measuring genuine social media performance, not only users who quit using social media but also dormant ones with reduced social media consumption should be included.

Since users who stop using social media completely cannot be considered participants in social media performance but rather negative influences on genuine long-term performance of platforms, this study also aims to consider dormant accounts as loss of social media performance. Since both closed and abandoned accounts could easily be exaggeration in social media performance, it is more appropriate to examine dormant users as negative like those who wholly shut down their accounts when measuring social media performance.

\subsection{Importance of Social Media Discontinuance Behavior}

Discontinuance intention is defined as the intention of an individual to reduce their use frequency of a particular product or service and to no longer use it or to switch to another product or service. In the context of social media, users have begun to discontinue using social networks that they used 
to use. Qzone, once the third largest social media platform in China, also lost popularity in 2015, and users identified that they wanted to quit and to move to private, closed SNS platforms, such as WeChat [5].

In this study, we regard social media discontinuance behavior as not only opting out, which is user avoidance of particular social media platforms, but also oblivion, which describes a gradual reduction in social media usage [7]. Oblivion is a reduction in users' perception of a system as convenient and useful among many factors that determine the quality of the information system. Since information systems are used for various purposes across different fields, usability is a concept that has been measured and structured in different ways with the development of information systems [8]. It is a somewhat ambiguous and subjective concept, but it has the advantage of being able to clearly evaluate a specific information system.

The determining factor of social media discontinuance behavior has been explained in various ways. Users' discontinuance intention could be explained by stimulus needs, WOM (word of mouth), and curiosity resulting from various needs, tastes, and constraints in previous studies [22]. To make the right decision on which social media platform to use, users are more likely to trust information acquired through reference groups or WOM and to select new products or services based on them. Therefore, WOM can influence users' discontinuance behavior [22]. Discontinuance behavior is also inhibited by factors such as satisfaction and habit or is caused by perceptions such as guilt, self-efficacy to discontinue, and social overload [23,24].

Dissatisfaction with social media's features or services may induce users' cessation of social media usage [25]. Social media discontinuance is especially relevant in situations where users consider it problematic, such as when they are overwhelmed by updated technology or perceive their individual privacy to be at risk [23]. In such a situation, users might intend to stop using the technology to avoid the overwhelming situation by changing their behavior and might then develop discontinuous usage intentions [8]. The following section provides an overview of prior research on fatigue that supports the present study's theoretical assumptions.

\subsection{An Overall Process Driving Social Media Discontinuance Behavior}

\subsubsection{Social Media Fatigue Driving Discontinuance Behavior}

It is necessary to reexamine social media performance by considering that users' discontinuance behavior cannot be regarded as performance achieved by social media platforms; there is a need to systematically recognize the factors that induce users' discontinuance behavior.

Different definitions for fatigue have been suggested by researchers in different fields [26,27]. In clinical studies, fatigue is described as a subjective feeling of tiredness, "an overwhelming sense of tiredness, lack of energy, and a feeling of exhaustion associated with impaired physical and cognitive functioning" [28]. In psychology studies, fatigue is defined as "reduced force production, loss of exercise capacity, increased sense of effort or perception of force" [29]. From the above definition, social media fatigue is defined as social media users' tendency to back away from social media usage when they become overwhelmed with too many sites, too many pieces of content, too many friends and contacts, and too much time spent keeping up with these connections [30]. In recent years, an increasing number of social media users fade away from social media platforms because they are experiencing tiredness, a phenomenon defined as "social media fatigue" [31], caused by some social media stress-creating conditions such as too much information and too many friends and contacts [23]. Social media platforms such as Facebook and Twitter have reportedly caused user dissatisfaction by exceeding the personal information exposure risk by providing too many contacts or an overload of information which users do not really need [32,33]. Based on the above definitions, social media fatigue can be described as social media users' tendency to fade away from social media usage when they become exhausted by too many contacts, too much information, and too many followers [23]. Users who feel exhausted when using social media may also consider that they are wasting too much 
time on specific platforms and feel that they are forced to consciously determine their relationships on social media, to which is difficult to adapt.

\subsubsection{Stressors Driving Social Media Fatigue}

Social media fatigue has been explained in various ways in previous research. Prior studies have mostly focused on stressors that cause social media fatigue. The stressors inducing social media fatigue can be mainly divided into technostress and socialstress [8]. Technostress refers to the stress social media users feel when they use information technology [34]. Information and communication technologies (ICT) engage people in heavy use of social media. Although providing convenience to users, excessive use and rapid ICT evolution can cause users to feel stressed [35]. Technostress creators include techno overload, techno invasion, techno complexity, techno insecurity, and techno uncertainty [36]. These technostress creators are also applicable to social media fatigue. Based on this, the authors of [37] divided technostress into social interaction overload, invasion of work, and invasion of privacy and examined the relationship between these technostress creators and social media fatigue. The authors of [23] empirically validated technostress creators (social overload) as the determinants of social media fatigue. Stress creators experienced while using social media can cause discontinued use. Furthermore, the authors of [38] identified overload as a representative stressor of technostress. Based on this, the authors of [35] proposed that information, social, and system feature overload can be directly linked to social media fatigue.

On the other hand, socialstress refers to the stress felt by individuals when they perceive that they pay too much attention to others' demands [9]. The main purpose of social media is social connection; thus, socialstress is important for understanding social media's negative consequences, such as social media fatigue and discontinuous usage [23]. However, less research has explored social media fatigue from the psychological perspective. Several psychological factors can contribute to social media fatigue, including depression and anxiety [10,11]. Anxious and depressed users show high engagement in compulsive social media use to relieve themselves from stressful symptoms, and their excessive social media use results in social media fatigue. Table 2 illustrates features of social media fatigue that have been discussed in previous studies. The various features were used by different authors to examine social media fatigue among social media users. The ticks indicate features used by different authors to examine social media fatigue.

Table 2. Studies examining antecedents of social media fatigue.

\begin{tabular}{|c|c|c|c|c|c|c|c|c|}
\hline \multicolumn{9}{|c|}{ Antecedents of Social Media Fatigue } \\
\hline Authors & $\begin{array}{c}\text { Techno } \\
\text { Complexity }\end{array}$ & $\begin{array}{c}\text { Social } \\
\text { Overload }\end{array}$ & $\begin{array}{l}\text { Information } \\
\text { Overload }\end{array}$ & $\begin{array}{l}\text { Invasion of } \\
\text { Privacy }\end{array}$ & $\begin{array}{c}\text { Invasion } \\
\text { of Work }\end{array}$ & $\begin{array}{c}\text { System Feature } \\
\text { Overload }\end{array}$ & Depression & Anxiety \\
\hline [22] & $\sqrt{ }$ & $\sqrt{ }$ & $\sqrt{ }$ & & & $\sqrt{ }$ & & \\
\hline [39] & & & $\sqrt{ }$ & $\sqrt{ }$ & & & & \\
\hline [35] & $\sqrt{ }$ & & $\sqrt{ }$ & & & $\sqrt{ }$ & & \\
\hline [40] & & $\sqrt{ }$ & $\sqrt{ }$ & & & $\sqrt{ }$ & & \\
\hline [11] & & & & & & & $\sqrt{ }$ & $\sqrt{ }$ \\
\hline [37] & & $\sqrt{ }$ & & $\sqrt{ }$ & $\sqrt{ }$ & & & \\
\hline [41] & & $\sqrt{ }$ & $\sqrt{ }$ & & & & & \\
\hline [10] & & & & & & & $\sqrt{ }$ & $\sqrt{ }$ \\
\hline [41] & & $\sqrt{ }$ & $\sqrt{ }$ & & & & & \\
\hline [9] & & & $\sqrt{ }$ & & & $\sqrt{ }$ & & \\
\hline
\end{tabular}

Socialstress plays an important role in understanding social media fatigue, but little research has studied it from the users' psychological perspective. The characteristics of social media, for example, Facebook's mission "to make the world more open and connected", encourage users to show themselves on social media [42]. The higher the level of self-disclosure that individual has, the stronger the social 
demand that they experience [43]. Thus, it is reasonable to assume that self-disclosure is related to socialstress. Furthermore, socialstress, which refers to the stress of excessive social demands, could result in social media fatigue [22]. More so, in recent years, a psychological term, "Fear of missing out" (FoMO), which refers to the desire to stay continually connected with what others are doing, has been widely applied in the research of social media use [44]. Various FoMO studies have suggested that high levels of FoMO have negative psychological and physiological consequences [12,45]. Individuals with high levels of FoMO are more likely to excessively engage in social activities, resulting in socialstress. Therefore, it is likely that high levels of FoMO and self-disclosure could induce social media fatigue indirectly despite the relative lack of studies on this topic.

\subsection{Social Media Involvement}

Involvement is usually defined as "a person's perceived relevance of the object based on inherent needs, values, and interests" [46]. The role of involvement in products or services has long been studied, and many important marketing models have addressed its conceptualization and measurement. The degree of attention and elaboration is indicative of one's involvement level. The level of involvement impacts the degree of learning and the effect of a communication message on its recipients [47-50]. Moreover, a high level of involvement leads to greater attention and interest in the product or service and a more positive attitude towards both. Studies have also demonstrated that involvement significantly affects users' processing of information and their behavioral intentions, thus mediating users' discontinuance behavior [46].

Regarding the extent of enthusiasm that individuals feel when they care deeply about the products or services [48], it is also viewed as a multidimensional concept that comprises not only behavioral (actions) but also cognitive (thoughts) and emotional (feelings) aspects [49]. Based on this, social media involvement can be regarded as the intensity of social media activities and the frequency with which social media users engage in them [50]. The authors of [46] conceptualized the levels of individuals according to their tendency to communicate, share, or promote activities in a social information exchange process. Generally, social media involvement manifests through posting pictures, connecting with friends, logging in frequently, and using social media credentials to log in to other sites, along with completeness of personal information provided on individuals' profiles [46]. On YouTube, social media involvement is manifested through user activities such as liking, disliking, commenting, sharing, uploading videos, and viewing videos [50]. Figure 1 illustrates how technostress and socialstress positively cause fatigue in social media users, thus increasing users' discontinuance behavior.

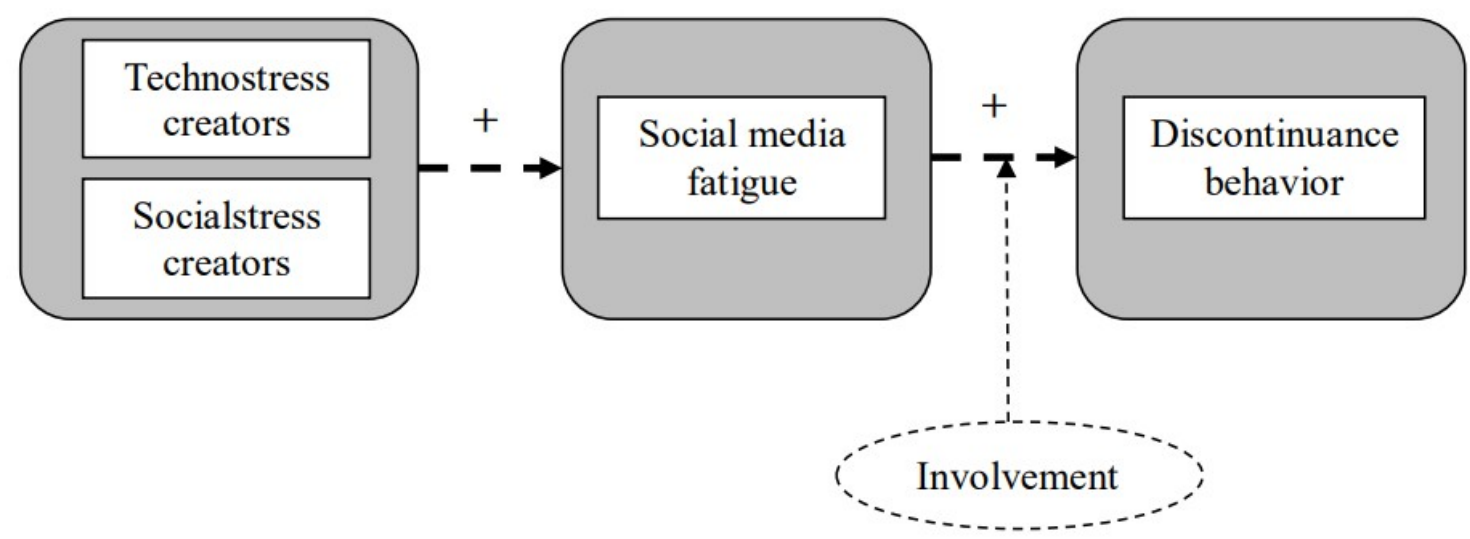

Figure 1. An overall process driving social media discontinuance behavior.

Therefore, the present study seeks to contribute to the literature involving social media discontinuance behavior through investigating social media fatigue, which greatly drives users' discontinuance behavior, by paying attention not only on technostress creators but also on users' psychology traits involving self-disclosure and fear of missing out that induce socialstress. Moreover, 
beyond the overall process, this study also tends to suggest social media involvement as a significant mediating role and to see through its controlling effects during the whole process.

\subsection{Research Hypotheses}

\subsubsection{Technostress Creators and Social Media Fatigue}

With the increasing use of social media, the issue of privacy has become ever more important especially in the online environment [10]. Research has proposed that privacy is a concern which most social media users consider [51]. Social media has the potential to facilitate privacy breaches as many social media platforms have integrated location-based services that make users' specific locations transparent to others [52]. This can make users feel pressured and can ultimately induce negative attitudes towards social media use [53]. Despite this, strategies from social media platforms still do not pay much attention to protecting user information. Consider, for example, how Facebook continues to maintain a liberal privacy viewpoint and how Google recently announced major changes to privacy among its properties. The authors of [39] found that individuals with higher privacy concerns were more likely to experience social media fatigue and to further cause social media discontinuance behaviors.

Furthermore, with the development of information technology, social media creates a channel in which individuals can not only disclose themselves but also have more channels to gain information than before. However, this vast information can be irrelevant or can even appear to be "junk" information, such as gossip or product advertising [41]. Excessive information can be a burden on social media users since the information processing requirement exceeds their processing capability.

Information which exceeds the needs of individuals burdens and confuses them, influences their ability to set priorities, and makes prior information much harder to recall [54]. The outcomes of overload are fatigue and feelings of stress. That is, higher levels of perceived information overload significantly predict greater stress [55].

In addition to information overload and privacy invasion, technology complexity is an antecedent of social media fatigue in prior research. Technology complexity in working situation is the degree of effort required to use the technology [35]. Prior research has shown that information technologies are becoming more and more complex [56]. However, this is in opposition to the original intention of individuals using SNS. Unlike professional technology in work contexts, individuals use social media in nonworking environments to seek entertainment and to pass time $[8,57]$. Further, research has shown that individuals use social media applications much more frequently than ever before; thus, the technology of social media cannot be too complicated and needs to be easily mastered and used [58]. If users find that the technology of social media is too difficult to master and that they need to spend time and effort to learn how to use it, they may feel frustrated and anxious, which results in social media fatigue [59]. This is consistent with the limited capacity model, according to which there is a capacity limit for humans to process added features. Moreover, according to cognitive load theory, human cognitive overload arises when the individual's cognitive resources require completing a task which exceeds the resources retained in their cognitive structure. If the technology of social media is highly complex for users and they perceive that the costs of learning and using the social media's features outweigh their benefits, social media fatigue occurs. Hence, we develop the following hypotheses:

Hypothesis 1 (H1): Privacy invasion has a positive effect on social media fatigue.

Hypothesis 2 (H2): Information overload has a positive effect on social media fatigue.

Hypothesis 3 (H3): Technology complexity has a positive effect on social media fatigue. 


\subsubsection{Socialstress Creators and Social Media Fatigue}

Social overload is described as a situation in which users perceive too many social demands, such as being responsible for friends, helping them solve their problems, or pleasing them in the online space [60]. The authors of [61] proposed the socialstress concept in social psychology. When the number of users increases, individuals have to increase social contacts and connections, which can result in negative consequences, such as stress and abandoning social contacts. SNSs are like virtual societies, with socialstress existing in this context. It is likely that individuals feel stressed on social media when they perceive that they pay too much attention to others' demands [9]. Such responsibilities are stressful due to unwanted social demands, including receiving too many friend requests from casual acquaintances, paying too much attention to friends' posts on social media, and taking too much care of friends' well beings on social media. These excessive communications which exceed individuals' demands may disrupt their daily life or work and may cause feelings of depression and confusion [40].

Self-disclosure is described as individuals voluntarily and intentionally revealing themselves to others, including thoughts, feelings, and experiences [62]. According to social exchange theory (SET), the motives of individual's self-disclosure could be explained in three ways. First, the intention that individuals want to exchange their thoughts and emotions can drive individuals engaging in self-disclosing [63]. SET views interpersonal interactions from a cost-benefit perspective; cost and benefit are able to determine knowledge-sharing behavior. Self-disclosure is regarded as an intrinsic benefit when it is higher than the perceived costs [64]. Furthermore, when an individual expects someone else to do the same things as themselves, receiving an intangible benefit, they are engaged in self-disclosure [62]. As such, self-disclosure is not only a factor of social media use but also a motivation for social communications.

To satisfy their needs for social communication and to receive social recognition, social media users with higher levels of self-disclosure are more likely to update their status or profile pictures frequently [65]. According to a research of the Pew Internet and American Life Project, the purpose for individuals using social media is to maintain contact with current friends and family as well as to reestablish connections with old friends [43]. Thus, it is not surprising that social media is characterized by high amounts of self-disclosure because it is a crucial element in relationship development [66]. Accordingly, it is reasonable to assume that the higher the self-disclosure levels that users have, the more likely they will perceive social overload.

With the development of internet technology and computing environments, social media users are surrounded by a huge amount of network information. As users' dependence on social media increases dramatically, their emotion and decisions are easily affected, especially when they browse social networking sites like Facebook, Twitter, and other social networking sites, which constantly provide timely feedback on the latest development of their friends' activities [42].

FoMO is a pervasive apprehension that others might have rewarding experiences from which one is absent. It is characterized by the desire to stay continuously connected with what others are doing $[67,68]$. Specifically, users are worried about missing a party, vacation, or any other social event and that they cannot refuse any offer [69]. Based on the compensatory internet use theory [70], people may turn to online spaces to satisfy psychological needs such as relatedness. To seek this sense of relatedness, individuals with higher levels of FoMO are more sensitive about their social bonds. The higher the level of FoMO that they have, the more they are likely to continuously connect with others and to update themselves on what others are doing [71]. Thus, it is reasonable to assume that FoMO is positively associated with social overload. Hence, we tend to suppose the following:

Hypothesis 4 (H4): Self-disclosure has a positive effect on social overload.

Hypothesis 5 (H5): FoMO has a positive effect on social overload.

Hypothesis 6 (H6): Social overload has a positive effect on social media fatigue. 


\subsubsection{Social Media Fatigue and Discontinuance Behavior}

Social media fatigue is related mostly to stressors, to which individuals may have negative emotions such as tiredness, boredom, indifference, and lower interest [40]. Users' reactions to these negative emotions, such as trying to avoid stressful situations, can change their behavior and can consequently cause them to have a stronger intention to discontinue using social media [72].

Prior research suggested that an individual who is exhausted from doing something develops an intention to change his or her behavior or an intention to discontinue the stressful behavior [72,73]. Users exhausted from social media can decide to discontinue social media use $[9,24,72]$. Social media fatigue can result in shorter social media browsing times, a reduction of usage, a decrease in enthusiasm, and promotion of negative impressions and attitudes toward social media. In this study, we use the term oblivion, which refers to gradually reducing usage behavior, and opt out, which refers to avoidance of social media behavior, to explain the social media discontinuance behavior. Thus, we suppose the following:

Hypothesis 7 (H7): Social media fatigue has a positive effect on oblivion.

Hypothesis 8 (H8): Social media fatigue has a positive effect on opt out.

\subsubsection{The Mediating Role of Involvement}

Previous studies have proven that individuals who are strongly involved in social media are emotionally attached to social media easily. They feel distressed when they cannot use social media, and they fail to reduce their social media usage [74]. It was also suggested that individuals with high levels of social media involvement generally have more years of experience in social media and more friends on social media than individuals with low levels of involvement. Thus, even though information overload, social overload, and privacy invasion risk could cause user discontinuance behavior, high levels of involvement could weaken the influence of social media fatigue on users' discontinuance behavior.

On the other hand, individuals with low levels of social media involvement generally have limited interest in using social media due to information overload or invasion privacy. Low-level involvement would make the influence of social media fatigue on discontinuance behavior much stronger. Thus, we developed the hypotheses below:

Hypothesis 9 (H9): Involvement will mediate the effect of social media fatigue on discontinuance behavior.

Hypothesis 9a (H9a): The effect of social media fatigue on oblivion will be weakened when the level of involvement is high.

Hypothesis $9 \mathbf{b}(\mathbf{H 9 b})$ : The effect of social media fatigue on oblivion will be strengthened when the level of involvement is low.

Hypothesis 9c (H9c): The effect of social media fatigue on opt out will be weakened when the level of involvement is high.

Hypothesis 9d (H9d): The effect of social media fatigue on opt out will be strengthened when the level of involvement is low. 


\section{Material and Method}

\subsection{Sampling}

This study seeks to investigate factors leading to social media fatigue and the effect of fatigue on user behavior. For this purpose, respondents who represent social media users from Gyeonggi province, South Korea were selected as research targets on the basis of their rich experiences using SNS actively. These respondents were asked to answer the designed questions according to their general experiences using SNS. For example, in the question on privacy invasion, they were required to indicate their feelings on whether their privacy information could be traced easily because of activities on SNS.

In addition, this study applied quota sampling reflecting gender, age, usage level, and occupation in order to collect the sample of social media users and to accurately reflect the characteristics of the population.

The quota sampling comprised two steps. The first step was to select the cities from Gyeonggi province in South Korea. Gyeonggi province is the largest province in south Korea. Approximately 40 percent of the country's population resides in this province. After the selection of cities, the researchers conducted the second step, which was to select respondents from the various cities. The researchers were able to distribute the questionnaire electronically using Google forums to reach more people by sending direct messages with the survey link to respondents through Kakaotalk and Facebook messages and by sharing the link on some Facebook groups. In order to motivate respondents, online coupons were presented as a reward for their participation. Besides using online sites to share questionnaires, the researchers visited some of these cities and began to approach respondents. Respondents who accepted filling out the questionnaires were presented with a small souvenir as a reward for participating in the research project.

Online and offline, a total of 250 questionnaires were distributed and 232 questionnaires were considered valid for the analysis; 18 questionnaires were not answered properly and were excluded.

\subsection{Constructs and Measurement Items}

This study constructed measurement items by using previous studies for each variable. Some of the measurement items were adapted directly from previous studies. For example, the same measurement items from [75] were used to measure social media fatigue, while others were modified to fit the objective of this study. A confirmatory analysis test was performed to confirm that the items measuring the various constructs were valid. The questionnaire used consisted of five-point Likert scales with anchors ranging from "strongly disagree $(=1)$ " to "strongly agree (=5)". Except for 4 demographic variables, 29 items were designed for 9 constructs. The measurement items were collected from different previous researches and modified in order to match the current research context appropriately, as shown in Table 3.

Items measuring privacy invasion were adapted and modified from those developed by [37]. Measurements of information overload were developed on the basis of the concepts introduced by [39]. As a means of testing the technology complexity, three questions were generated based on concepts from the study of [72]. Measurement items from [76] were adopted and developed to measure users' self-disclosure. FoMO was assessed by developing four item questions according to [67]. Measurement items from [40,75] were used to measure social overload and social media fatigue, respectively. Measurement items from $[77,78]$ were used to test opt out and oblivion, respectively. To measure social media involvement, concepts from [79] were adapted and used. 
Table 3. Measurement item.

\begin{tabular}{|c|c|c|}
\hline Constructs & Measurement Items & Researcher \\
\hline Privacy invasion & $\begin{array}{l}\text { I usually have this awkward feeling that using SNS can be monitored easily. } \\
\text { I often feel that my activities using SNS can be traced easily and, as such, my privacy } \\
\text { will be compromised. } \\
\text { I often feel that my privacy using SNS can be breach by my employer via tracking } \\
\text { my activities. } \\
\text { I often feel that social media makes me provide a lot of personal information. }\end{array}$ & [37] \\
\hline Information overload & $\begin{array}{l}\text { I think the huge amount of information available on social media often troubles me. } \\
\text { I usually feel that, on a daily basis, the quantity of information that I have to process } \\
\text { on social media is overwhelming. } \\
\text { I usually discover that, while using social media, only a small part of the information } \\
\text { is relevant to me. } \\
\text { I think there is lots of information on social media regarding my friends which is } \\
\text { generally difficult for me to handle. }\end{array}$ & [39] \\
\hline \multirow{3}{*}{ Technology complexity } & In general, social media is difficult to control. & \multirow{3}{*}{ [72] } \\
\hline & $\begin{array}{l}\text { The features of the social media that I use are often more complicated than the tasks I } \\
\text { have to do using these features. }\end{array}$ & \\
\hline & Social media usually makes me feel that I have little control over my activities. & \\
\hline Self-disclosure & $\begin{array}{l}\text { Generally, I have a detailed profile on social media. } \\
\text { Normally, I upload huge amounts of information about myself on social media. } \\
\text { Generally, I do not bother placing my personal information on social media. } \\
\text { My profile picture on social media usually tells a lot about me. }\end{array}$ & [76] \\
\hline FoMO & $\begin{array}{c}\text { Overall, I worry that social media gives rewarding experiences to users other } \\
\text { than me. } \\
\text { Overall, I get worried knowing that my friends are having fun on social media } \\
\text { without me. } \\
\text { Overall, not knowing what my friends are doing on social media makes me worried. } \\
\text { Overall, when I have a good time, I feel it is necessary to share my detailed } \\
\text { information online. }\end{array}$ & [67] \\
\hline Social overload & $\begin{array}{l}\text { Usually when I am using social media, I tend to focus more on my friend's post. } \\
\text { On social media, I usually show a lot of care towards my friends' welfare. } \\
\text { While using social media, casual associates often send me friend requests. }\end{array}$ & [40] \\
\hline Social media fatigue & $\begin{array}{l}\text { Generally, when using social media, I feel exhausted. } \\
\text { Generally, I waste a huge amount of my time on social media. } \\
\text { Generally, using social media puts me under a lot of pressure. }\end{array}$ & [75] \\
\hline Social media Involvement & $\begin{array}{l}\text { When I learn of a new social media site, I will hastily invite my friends to join. } \\
\text { Usually, I log onto social media sites at least once a day. } \\
\text { This social media site's ability to expand social relationships is better than other } \\
\quad \text { social media sites overall. } \\
\text { This social media site's ability to share information is in a timely manner overall. } \\
\text { This social media site's ability to manage social relationships is effective overall. }\end{array}$ & [79] \\
\hline Oblivion & $\begin{array}{l}\text { This social media site makes me think of decreasing my time of use, generally. } \\
\text { This social media site makes me want to use the service less frequently, in general. } \\
\text { This social media site no longer draws my interest overall. }\end{array}$ & [80] \\
\hline Opt out & $\begin{array}{l}\text { This social media site usually makes me regret choosing this service. } \\
\text { This social media site usually makes me want to unregister. } \\
\text { the future. } \\
\text { This social media site usually makes me want to use another social network site in } \\
\text { This social media site makes me want to use it far less than today } \\
\text { in the future, generally. }\end{array}$ & [77] \\
\hline
\end{tabular}

\section{Results}

\subsection{Sample Characteristics and Correlations}

The questionnaire in this study was conducted through online and offline surveys in Gyeonggi province, South Korea. A total of 250 questionnaires were distributed, of which 232 were valid questionnaires. According to the sample statistics, the gender difference was not large, with 105 males $(45.3 \%)$ and 127 females (54.7\%) participating. As far as the age structure of the sample is concerned, $72(31.1 \%)$ of them were between 20 to 29 years, 94 (40.5\%) were between 30 to 39 years, $42(18.1 \%)$ were between 40 to 49 years, and $24(10.3 \%)$ were over 50 years. The average daily social media access 
times were $38.4 \%$ for $1 \mathrm{~h}$ to $3 \mathrm{~h}$, followed by $32.8 \%$ for $30 \mathrm{~min}$ to less than $1 \mathrm{~h}, 42$ (18.1\%) for more than $3 \mathrm{~h}$, and $25(10.7 \%)$ for less than $30 \mathrm{~min}$. For occupation of respondents, students were the highest, with 117 (50.5\%), followed by officers (62; 26.6\%), self-employers (31; 13.4\%), and others $(22 ; 9.5 \%)$. The characteristics of the sample are detailed in Table 4 below.

Table 4. Demographic characteristics.

\begin{tabular}{|c|c|c|c|}
\hline Item & Characteristics & Frequency & Ratio \\
\hline \multirow{3}{*}{ Gender } & Male & 105 & $45.3 \%$ \\
\hline & Female & 127 & $54.7 \%$ \\
\hline & Total & 232 & $100 \%$ \\
\hline \multirow{5}{*}{ Age } & $20-29$ & 72 & $31.1 \%$ \\
\hline & $30-39$ & 94 & $40.5 \%$ \\
\hline & $40-49$ & 42 & $18.1 \%$ \\
\hline & Over 50 & 24 & $10.3 \%$ \\
\hline & Total & 232 & $100 \%$ \\
\hline \multirow{5}{*}{ Daily average social media access time } & Less than $30 \mathrm{~min}$ & 25 & $10.7 \%$ \\
\hline & $30 \mathrm{~min}-1 \mathrm{~h}$ & 76 & $32.8 \%$ \\
\hline & $1 \mathrm{~h}-3 \mathrm{~h}$ & 89 & $38.4 \%$ \\
\hline & More than $3 \mathrm{~h}$ & 42 & $18.1 \%$ \\
\hline & Total & 232 & $100 \%$ \\
\hline \multirow{5}{*}{ Occupation } & Student & 117 & $50.5 \%$ \\
\hline & Officer & 62 & $26.6 \%$ \\
\hline & Self-employed & 31 & $13.4 \%$ \\
\hline & Others & 22 & $9.5 \%$ \\
\hline & Total & 232 & $100 \%$ \\
\hline
\end{tabular}

Table 5 shows the mean, standard deviation, and correlation matrix of the constructs used in this study. Regarding correlation among constructs, social opt out showed the highest correlation with oblivion $(0.637, p<0.001)$. Between the relationship of technostress creators and users' social media fatigue, information overload was found to be correlated with social media fatigue at the highest level $(0.389, p<0.001)$. The relationship between social overload and social media fatigue showed a relatively high level of 0.325 ( $p<0.001$ ), whereas users' social media fatigue showed a higher relevance $(0.374, p<0.001)$ on oblivion compared to users' opt out of social media $(0.294, p<0.001)$.

\subsection{Measurement and Validation}

The research model (see Figure 2) in this study consists of eight constructs with interrelated causal paths, which requires a structural equation model (SEM) analysis. SEM analysis requires constructs to be assessed by confirmatory factor analysis (CFA) to examine convergent and discriminant validity. CFA results were obtained using the software package AMOS. Table 5 shows that $t$-values for all standardized factor loadings of items are significant at $p<0.001$, indicating item reliability. The evaluation was performed using the following three criteria: the composite reliability (CR) should be at least 0.7 [70], the average variance (AVE) of the extraction should be at least 0.4 and greater than 0.5 , and all projects loads should be greater than 0.7 [71]. As shown in Table 6, the composite reliability is from 0.774 to 0.927 and the average variance extracted values also meet the requirement of exceeding 0.40 at 0.494 to 0.794. As such, the convergefigurent validity of measures used in the study is demonstrated. 
Table 5. Correlations among constructs.

\begin{tabular}{|c|c|c|c|c|c|c|c|c|c|}
\hline Constructs & $\begin{array}{c}\text { Privacy } \\
\text { Invasion }\end{array}$ & $\begin{array}{l}\text { Information } \\
\text { Overload }\end{array}$ & $\begin{array}{l}\text { Technology } \\
\text { Complexity }\end{array}$ & Self-Disclosure & FoMO & $\begin{array}{c}\text { Social } \\
\text { Fatigue }\end{array}$ & $\begin{array}{c}\text { Social } \\
\text { Overload }\end{array}$ & Oblivion & Opt Out \\
\hline $\begin{array}{c}\text { Privacy } \\
\text { Invasion }\end{array}$ & 1.00 & & & & & & & & \\
\hline $\begin{array}{c}\text { Information } \\
\text { Overload }\end{array}$ & $0.253^{* * *}$ & 1.00 & & & & & & & \\
\hline $\begin{array}{l}\text { Technology } \\
\text { Complexity }\end{array}$ & 0.117 & $0.275^{* * *}$ & 1.00 & & & & & & \\
\hline Self-Disclosure & 0.038 & 0.022 & 0.059 & 1.00 & & & & & \\
\hline FoMO & 0.076 & 0.033 & 0.076 & 0.075 & 1.00 & & & & \\
\hline $\begin{array}{c}\text { Social } \\
\text { Fatigue }\end{array}$ & $0.318^{* * *}$ & $0.389^{* * *}$ & $0.15^{* *}$ & 0.075 & 0.031 & 1.00 & & & \\
\hline $\begin{array}{c}\text { Social } \\
\text { Overload }\end{array}$ & $0.353^{* * *}$ & $0.178^{* * *}$ & 0.117 & $0.189 *$ & $0.129 * *$ & $0.325^{* * *}$ & 1.00 & & \\
\hline Mean & 2.851 & 2.597 & 2.517 & 2.491 & 2.460 & 2.550 & 2.807 & 2.495 & 1.951 \\
\hline S.D. & 0.851 & 0.772 & 0.697 & 0.418 & 0.464 & 0.859 & 0.820 & 0.782 & 0.735 \\
\hline
\end{tabular}

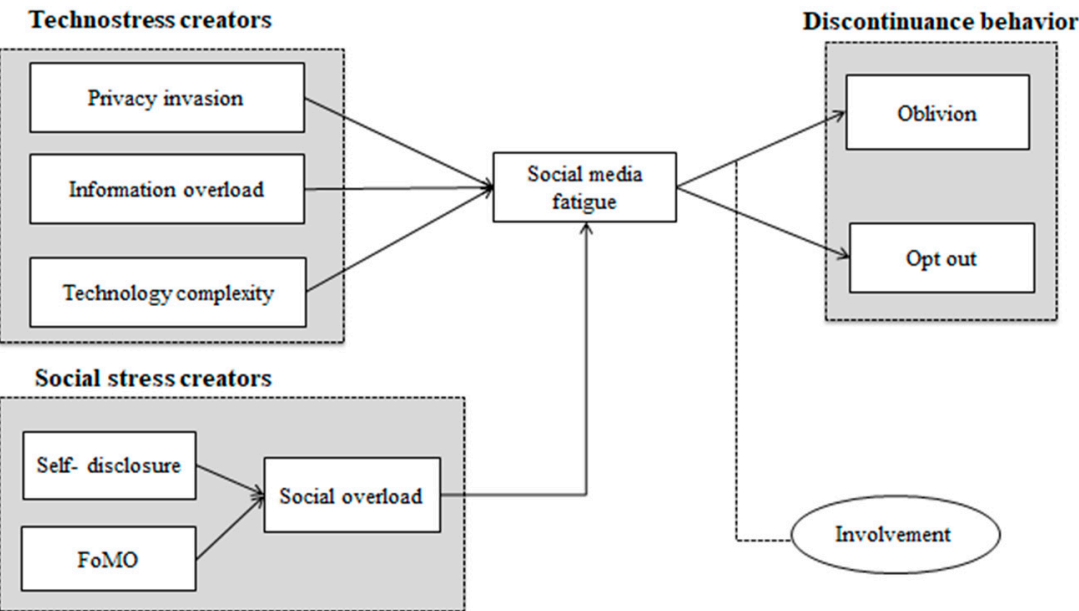

Figure 2. Research Model.

In addition, the authors of [80] suggested that loadings over 0.30 meet the minimal level, over 0.40 are regarded as more important, and over 0.50 are practically significant. The loading of items on their corresponding constructs should be greater than 0.32 , and loadings over 0.71 are excellent, over 0.63 are very good, over 0.55 are good, and over 0.45 are fair. Thus, in this study, all loadings appear to be significant loadings. 
Table 6. Confirmatory factory analysis (CFA) results.

\begin{tabular}{|c|c|c|c|c|c|c|c|}
\hline Constructs & Items & Factor Loading & S.E. & Std. Loading & $t$-Value & CR & AVE \\
\hline \multirow{4}{*}{ Privacy invasion } & PI1 & 1.000 & - & 0.552 & - & \multirow{4}{*}{0.784} & \multirow{4}{*}{0.510} \\
\hline & PI2 & 1.173 & 0.105 & 0.763 & $11.193^{* * *}$ & & \\
\hline & PI3 & 0.857 & 0.089 & 0.463 & $9.643^{* * *}$ & & \\
\hline & PI4 & 0.787 & 0.101 & 0.305 & $7.820 * * *$ & & \\
\hline \multirow{4}{*}{ Information overload } & IO1 & 1.000 & - & 0.320 & - & \multirow{4}{*}{0.850} & \multirow{4}{*}{0.600} \\
\hline & $\mathrm{IO} 2$ & 1.690 & 0.181 & 0.835 & $9.329 * * *$ & & \\
\hline & IO3 & 1.668 & 0.179 & 0.828 & $9.325 * * *$ & & \\
\hline & $\mathrm{IO} 4$ & 1.064 & 0.152 & 0.313 & $6.978 * * *$ & & \\
\hline \multirow{3}{*}{ Technology complexity } & TC1 & 1.000 & - & 0.473 & - & \multirow{3}{*}{0.774} & \multirow{3}{*}{0.568} \\
\hline & TC2 & 2.193 & 0.476 & 1.091 & $4.610^{* * *}$ & & \\
\hline & TC3 & 1.261 & 0.206 & 0.341 & $6.124^{* * *}$ & & \\
\hline \multirow{4}{*}{ Self-disclosure } & SD1 & 1.000 & - & 0.385 & - & \multirow{4}{*}{0.882} & \multirow{4}{*}{0.660} \\
\hline & SD2 & 1.456 & 0.293 & 0.318 & $4.964 * * *$ & & \\
\hline & SD3 & 1.849 & 0.346 & 0.552 & $5.342 * * *$ & & \\
\hline & SD4 & 1.727 & 0.324 & 0.496 & $5.326^{* * *}$ & & \\
\hline \multirow{4}{*}{ FoMO } & FM1 & 1.000 & - & 0.428 & - & \multirow{4}{*}{0.789} & \multirow{4}{*}{0.494} \\
\hline & FM2 & 1.507 & 0.377 & 0.345 & $3.993^{* * *}$ & & \\
\hline & FM3 & 1.793 & 0.443 & 0.437 & $4.052 * * *$ & & \\
\hline & FM4 & 1.351 & 0.340 & 0.332 & $3.976^{* *}$ & & \\
\hline \multirow{3}{*}{ Social media fatigue } & SF1 & 1.000 & - & 0.626 & - & \multirow{3}{*}{0.813} & \multirow{3}{*}{0.592} \\
\hline & SF2 & 0.996 & 0.091 & 0.597 & $10.906^{* * *}$ & & \\
\hline & SF3 & 0.976 & 0.094 & 0.533 & $10.424^{* * *}$ & & \\
\hline \multirow{3}{*}{ Social overload } & SS1 & 1.000 & - & 0.591 & - & \multirow{3}{*}{0.833} & \multirow{3}{*}{0.630} \\
\hline & SS2 & 1.115 & 0.105 & 0.825 & $10.583 * * *$ & & \\
\hline & SS3 & 0.730 & 0.078 & 0.404 & $9.403^{* * *}$ & & \\
\hline \multirow{3}{*}{ Oblivion } & OB1 & 1.000 & - & 0.690 & - & \multirow{3}{*}{0.855} & \multirow{3}{*}{0.597} \\
\hline & OB2 & 1.082 & 0.144 & 0.538 & $7.523^{* * *}$ & & \\
\hline & OB3 & 0.559 & 0.110 & 0.553 & $5.083 * * *$ & & \\
\hline \multirow{4}{*}{ Opt out } & OP1 & 1.000 & - & 0.692 & - & \multirow{4}{*}{0.927} & \multirow{4}{*}{0.763} \\
\hline & OP2 & 1.067 & 0.081 & 0.573 & $13.209^{* * *}$ & & \\
\hline & OP3 & 1.219 & 0.070 & 0.870 & $17.449^{* * *}$ & & \\
\hline & OP4 & 1.060 & 0.073 & 0.649 & $14.452 * * *$ & & \\
\hline
\end{tabular}

\subsection{Empirical Results}

To validate the research model, this study used structural equitation modeling (SEM) performed by AMOS before examining the causal relationship between concept variables. In general, the chi-square test used the following indexes to measure the fitness of the model: the significance level associated with chi-square $\left(\chi^{2}\right)$, the goodness of fit index (GFI), adjusted goodness of fit index (CFI), and root mean square error of approximation (RMSEA). Fitting the model indicates that the value is less than 3, with the GFIM, Normed-fit index NFI, CFI, and IIFIM values $\geq 90$; the AGFI value $\geq 80$; and the RMSEA value $\leq 0.08$ degree of freedom.

By using AMOS 18.0, the results of standardized path coefficients, $t$-value, and coefficients of determination of latent variables are shown in Figure 3. The results were as follows: $\chi^{2}=776.877$, $\mathrm{df}=446, \mathrm{GFI}=0.833, \mathrm{AGFI}=0.802, \mathrm{NFI}=0.767, \mathrm{CFI}=0.883$, Incremental fit indices $(\mathrm{IFI})=0.885$, 
and RMSEA $=0.057$. The $\mathrm{R}^{2}$ values of social media fatigue and social overload are $26 \%$ and $6.3 \%$, of oblivion is $26.9 \%$, and of opt out is $16.3 \%$. Thus, based on the results we obtained; the current research suggests that the model is statistically valid.

Technostress creators

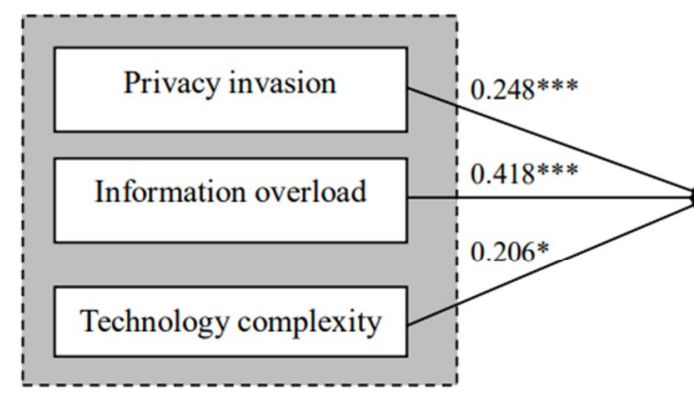

Social stress creators

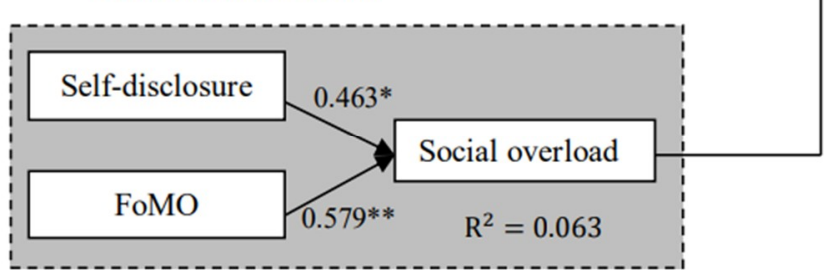

Discontinuance behavior

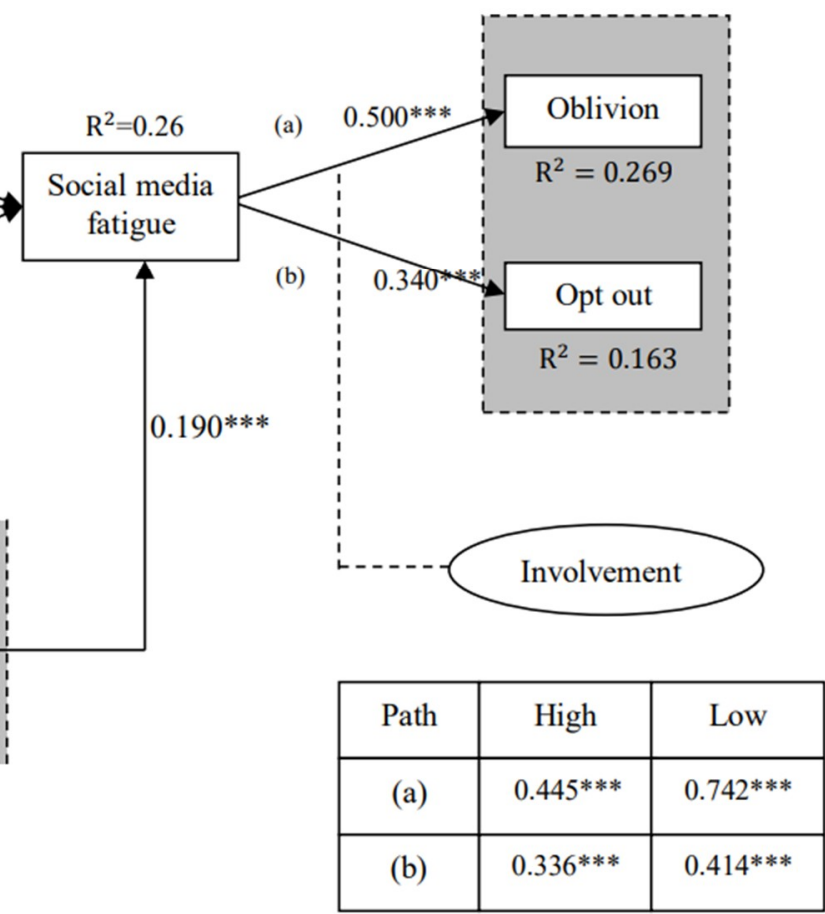

Figure 3. Causal effects among constructs. ${ }^{* * *} p<0.001,{ }^{* *} p<0.01$, and ${ }^{*} p<0.05 . \chi^{2}=776.877$, $\mathrm{df}=446$, the goodness of fit index $(\mathrm{GFI})=0.833$, AGFI $=0.802 ; \mathrm{NFI}=0.767$, adjusted goodness of fit index $(\mathrm{CFI})=0.883, \mathrm{IFI}=0.885$, and root mean square error of approximation $(\mathrm{RMSEA})=0.057$.

The survey results show that the antecedents of social media fatigue, that is, privacy invasion, information overload, and technology complexity, are significant and positively associated with social media fatigue $(\beta=0.248, p<0.001 ; \beta=0.418, p<0.001$; and $\beta=0.206, p<0.05)$. This result agrees with the findings of $[8,14]$. Therefore, hypotheses 1,2 , and 3 are supported. Also, social overload is positive and statistically significant $(\beta=0.190, p<0.001)$. This is supportive of hypothesis 6 . This finding is consistent with those of [13]. Compared with privacy invasion and technology complexity, information overload had the greatest impact on social media fatigue. This implies that too much information in social media can drive social media users to their limits for processing information and can cause fatigue [25].

At the same time, self-disclosure and FoMO, that we chose as the factors influencing social overload, also have a significant and positive influence on social overload. This suggests that hypotheses 4 and 5 are supported. The positive relationship is in line with $[37,38]$. FoMO was found to have higher coefficient $(\beta=0.579, p<0.01)$ compared with self-disclosure $(\beta=0.493, p<0.05)$. This can be explained by individuals who fear missing out, feeling compelled to check their social media more often to get an update on friend's plans and activities [81].

In the relationship between social media fatigue and discontinuance behavior, social media fatigue was found to have positive influence on both oblivion $(\beta=0.500, p<0.001)$ and opt out $(\beta=0.340$, $p<0.001)$. This result is in line with a similar study on social media fatigue and users' discontinuance behavior [14,21]. Therefore, hypotheses 7 and 8 were adopted (see Table 7). 
Table 7. Path analysis.

\begin{tabular}{cccc}
\hline & Path & Coefficient & Result \\
\hline H1 & Privacy invasion $\rightarrow$ Social media fatigue & $0.300^{* *}$ & Supported \\
\hline H2 & Information overload $\rightarrow$ Social media fatigue & $0.388^{* * *}$ & Supported \\
\hline H3 & Technology complexity $\rightarrow$ Social media fatigue & $0.163^{*}$ & Supported \\
\hline H4 & Self-disclosure $\rightarrow$ Social overload & $0.493^{*}$ & Supported \\
\hline H5 & FoMO $\rightarrow$ Social overload & $0.579^{* *}$ & Supported \\
\hline H6 & Social overload $\rightarrow$ Social media fatigue & $0.190^{* * *}$ & Supported \\
\hline H7 & Social media fatigue $\rightarrow$ Oblivion & $0.500^{* * *}$ & Supported \\
\hline H8 & Social media fatigue $\rightarrow$ Opt out & $0.340^{* * *}$ & Supported \\
\hline & ${ }^{* * *} p<0.001,{ }^{* *} p<0.01,{ }^{*} p<0.05$. & &
\end{tabular}

\subsection{The Mediating Effect of Social Media Involvement}

In this study, a multiple group analysis was used to investigate the influence of the level of social media involvement on the relationship between social media fatigue and social media discontinuance behaviors. According to the mean value dichotomizing method proposed by [73], the average of the measurement items of social media involvement is used as the standard $(\mathrm{M}=3.2)$. A total of 232 samples were divided into high-level and low-level groups; the group with a higher average has the higher level of involvement, and the group with the lower average has the lower level of involvement.

The multi-group results are summarized in Table 8. Between the relationship of social media fatigue and social media discontinuance behavior, the level of social media involvement was proven to mediate the relation between social media fatigue, oblivion, and opt out behavior. Therefore, hypothesis 9 was supported. The coefficient of low levels of involvement $(0.742, p<0.001)$ is nearly twice the high-level group of social media involvement $(0.445, p<0.001)$. Table 8 shows the difference in chi-square of the equivalent non-constraint model. The value is 4.513 and is statistically significant at the $1 \%(p<0.001)$ level. This confirms that a high level of involvement mediates the relationship between social media fatigue and users' oblivion behavior.

Table 8. Multi-group results according to social media involvement.

\begin{tabular}{|c|c|c|c|c|}
\hline \multicolumn{5}{|c|}{ Equality Constraint Model: $\chi^{2}=1201.209(\mathrm{df}=728), \chi^{2}{ }_{\text {crit }}=1.650(\Delta \mathrm{d} . \mathrm{f}=1, p<0.01)$} \\
\hline \multirow{2}{*}{ Path } & \multirow{2}{*}{$\Delta x^{2}$} & \multicolumn{2}{|c|}{ Cross-Group Path Coefficient } & \multirow{2}{*}{ Result } \\
\hline & & High Group & Low Group & \\
\hline Social media fatigue $\rightarrow$ Oblivion & 4.513 & $0.445^{* * *}$ & $0.742^{* * *}$ & Supported \\
\hline Social media fatigue $\rightarrow$ Opt out & 4.232 & $0.336^{* * *}$ & $0.414^{* * *}$ & Supported \\
\hline
\end{tabular}

As shown before, if we do not take the level of involvement into consideration, the coefficient of the relationship between social media fatigue and oblivion is $0.500(p<0.001)$, which is higher than 0.445 (high-level group) but lower than 0.742 (low-level group). Similarly, the coefficient of the relationship between social media fatigue and opt out is $0.340(p<0.001)$ before considering the level of involvement, which is also higher than the high-level group (0.336) and lower than the low-level group (0.414).

That is, social media involvement is the enthusiasm that users feel when they care deeply about the social media products or service. Previous studies [10,41] have proven that individuals who are strongly involved in social media are emotionally attached to social media. They feel distressed when they cannot use social media, and they unsuccessfully reduce social media use since they have so 
many friends on social media or have a deep connection with social media [64]. Thus, even though information overload, social overload, and privacy invasion risk would make social media users feel overwhelmed and drive them to quit social media platform or reduce their social media activities, a high level of involvement can weaken such an influence.

\section{Discussion and Conclusions}

In order to identify the existing method of measuring social media performance, this study adapted and modified most of the items used in measuring the construct. The majority of items were adapted from previous studies (Table 2). In order to confirm the validity of these items, a confirmatory analysis was performed. The theoretical implications of this study are summarized as follows. First, this study identified that existing methods of measuring social media performance through number of accounts or joining in are all exaggerated as social media users who leave their accounts dormant after registering and unintentional visiting or clicks are neglected. The genuine performance that social media platforms are eager to seek might be from users' constant and long-term registration, subscription, or visits, and not only users who quit social media but also those who gradually fade away from specific platforms should be regarded as a loss of social media performance. This study especially focuses on users' social media discontinuance usage and explored it from two perspectives, one of which is oblivion, involving the behavior that users gradually reduce social media usage, and the other of which is opt out, which refers to users' avoidance of social media. As the strongest effect of social media fatigue can be seen on users' oblivion behavior, if users suffer from social media fatigue, they will reduce their activities on social media but still keep the account rather than opt out from social media totally [9].

Second, this study is meaningful in that it explores the motivations of social media discontinuance from the views of technostress creators and socialstress creators through social media fatigue. Although a few studies have examined social media fatigue in terms of socialstress, it lacks studies examining social media fatigue from the perspective of users' social relationship and social connection psychologically. In this study, we examined users' fatigue on social media based on technostress and socialstress, which has been explored in terms of the individual's psychological perspective, which includes FoMO and self-disclosure. The analytical results in Figure 3 show that privacy invasion, information overload, technology complexity, and social overload have a positive impact on social media fatigue. This implies that technostress creators cause social media fatigue among social media users. Also, self-disclosure and FoMO have a significant and positive influence on social overload.

Thirdly, this study investigates the influence of involvement between social media fatigue and discontinuance behaviors. Users with high social media involvement generally have many contacts on social media or attachment to the services which are provided by social media. On the other hand, if there is so much information overwhelming the user or a perceived personal privacy risk, these users would easily fade away from the social media platform. Thus, different from studies that consider involvement as a cause of social media attachment, this study applied it in the relationship between social media fatigue and discontinuance behavior. From the above results, the level of involvement has a significant influence on users' oblivion and opt out behaviors. In relation to the results, a high level of social media involvement weakens users' oblivion and opt out behaviors. By recognizing the role of involvement in influencing discontinuance behavior, it could provide a new perspective to social media providers.

According to the findings, we present the following managerial implications. Firstly, this study proposed that social media fatigue has a positive influence on user's social media discontinuance behavior as well as reexamines the performances of social media platforms and explores genuine performance on social media. Previous studies have suggested social media dormant users as quantitative indicators and measured that as performance [82]. It is likely that dormant users who do not have any activity on social media are more likely to leave and tend to switch easily if a new alternative social media emerges. A number of studies have regarded these dormant users as a social 
media platform's performance. In addition, very little existing studies have investigated the causes of dormant users. In order to fill this gap, this study tries to elaborate on the social media performance measurement by using oblivion in the analysis measuring acceptance behavior of dormant users. As a result, social media fatigue was proven to have a strong influence on users' opt out behavior and, similarly, has a significant impact on oblivion. Therefore, it can be confirmed that users' dormant accounts should be taken into consideration when measuring social media performance.

Furthermore, the findings of the current study investigate both technostress and socialstress, and among the creators of the technostress, information overload plays a more significant role than technology complexity. Therefore, managers should add features to the social media platform such as personalization to let people have the ability to control content. For instance, TikTok, the emerging social media in China, provide services by applying customized algorithms and to push content that users might like according to the user's search history, thereby reducing information overload [32,42]. Similarly, JinriToutiao, which is a content platform for news and information from China, not only exposes personalized information to users but also provides services which users can select to use system functions [83].

More so, among the creators of the socialstress, FoMO is more highly significant than self-closure $(p<0.00)$. Since FoMO means the fear of getting excluded from the mainstream, social media users desire to have a better and more interesting connection with surrounding people [84]. From this point, social media providers should also consider the influence of users' psychological traits when making strategies $[85,86]$.

\section{Limitations and Future Research}

Although this study provides the above conclusions and recommendations to academics and practitioners, its inherent limitations must be stated.

First, further analysis involving different serving types or classifications of social media would further our understanding of social media performance. Due to the variety of widely used social media platform, such as Facebook, Instagram, KakaoTalk, and WeChat, the potential factors of social media fatigue may differ according to the functions provided by each social media platform. Therefore, to present more practical implications for social media companies, future research should choose a specific platform for its research objective and should explore the factors that may cause social media fatigue according to unique functions or features.

Second, the samples selected for this study have a demographic limitation which could affect the results. Approximately half of the participants selected were students. Although the population characteristics of our sample are similar to general social media users, the result may differ depending on the occupation of the participants [87]. For example, compared with students, individuals who work will be concerned about potential privacy and work invasions. Further research should select more diverse samples; using larger samples might also produce different results.

Third, since the items in this study were adapted and modified from previous studies, future research could use the same items without modifying them to evaluate the performance of social media.

Furthermore, users' stress proposed in this study, such as technostress or perceived socialstress in social media use, were identified as the main determining factors of users' fatigue. This study was limited in this evaluation as the implication of change in time was not analyzed. Thus, a longitudinal study is necessary to investigate time-variant impacts on social media usage.

Apart from this, future research should explore other factors and outcomes of social media fatigue, such as social media fatigue from various academic points of view. Since young individuals like students form a large part of social media users, future research should examine whether social media fatigue can influence students' educational outcomes. 
Author Contributions: All authors listed have made substantial, direct, and intellectual contributions to the work and approved it for publication. I.K., and S.Y. designed the model and analysed the data. Y.Z. Wrote the manuscript with input from al the authors. All authors have read and agreed to the published version of the manuscript.

Funding: The authors declare that the research was conducted in the absence of any commercial or financial relationships that could be construed as a potential conflict of interest.

Conflicts of Interest: The authors declare no conflict of interest.

Data Availability Statement: Datasets are available upon request.

\section{References}

1. Learn BONDS. Available online: https://learnbonds.com/news/facebook-users-in-the-us-exceeded-70-of-itsentire-population/ (accessed on 12 December 2019).

2. Statista. Available online: https://www.statista.com/statistics/1011415/south-korea-number-of-social-mediausers-by-platform/ (accessed on 12 December 2019).

3. Hui, S.K. Understanding repeat playing behavior in casual games using a Bayesian data augmentation approach. Quant. Mark. Econ. 2017, 15, 29-55. [CrossRef]

4. Lacka, E.; Chong, A. Usability perspective on social media sites' adoption in the B2B context. Ind. Mark. Manag. 2016, 54, 80-91. [CrossRef]

5. Zhang, D.; Feng, X.; Chen, P. Examining microbloggers' individual differences in motivation for social media use. Soc. Behav. Personal. Int. J. 2018, 46, 667-681. [CrossRef]

6. Pew Research Center. Available online: https://www.pewresearch.org/fact-tank/2018/09/05/americans-arechanging-their-relationship-with-facebook (accessed on 12 December 2019).

7. Moll, R.; Pieschl, S.; Bromme, R. Blessed oblivion? Knowledge and metacognitive accuracy in online social networks. Int. J. Dev. Sci. 2015, 9, 57-60. [CrossRef]

8. Xiao, L.; Mou, J. Social media fatigue-Technological antecedents and the moderating roles of personality traits: The case of WeChat. Comput. Hum. Behav. 2019, 101, 297-310. [CrossRef]

9. Shokouhyar, S.; Siadat, S.H.; Razavi, M.K. How social influence and personality affect users' social network fatigue and discontinuance behavior. Aslib J. Inf. Manag. 2018, 70, 344-366. [CrossRef]

10. Dhir, A.; Yossatorn, Y.; Kaur, P.; Chen, S. Online social media fatigue and psychological wellbeing-A study of compulsive use, fear of missing out, fatigue, anxiety and depression. Int. J. Inf. Manag. 2018, 40, 141-152. [CrossRef]

11. Khan, A.; Asghar, M.; Ahmad, H.; Kundi, F.; Ismail, S. A Rule-Based Sentiment Classification Framework for Health Reviews on Mobile Social Media. J. Med. Imaging Health Inform. 2017, 7, 1445-1453. [CrossRef]

12. Baker, Z.G.; Krieger, H.; LeRoy, A.S. Fear of missing out: Relationships with depression, mindfulness, and physical symptoms. Transl. Issues Psychol. Sci. 2016, 2, 275. [CrossRef]

13. Davis, K. Friendship 2.0: Adolescents' experiences of belonging and self-disclosure online. J. Adolesc. 2012, 35, 1527-1536. [CrossRef]

14. Murdough, C. Social media measurement: It's not impossible. J. Interact. Advert. 2009, 10, 94-99.

15. Hoffman, D.L.; Fodor, M. Can you measure the ROI of your social media marketing? MIT Sloan Manag. Rev. 2010, 52, 41.

16. Wang, C.; Lee, M.K.; Hua, Z. A theory of social media dependence: Evidence from microblog users. Decis. Support Syst. 2015, 69, 40-49.

17. Ding, Y.; Du, Y.; Hu, Y.; Liu, Z.; Wang, L.; Ross, K.; Ghose, A. Broadcast yourself: Understanding YouTube uploaders. In Proceedings of the 2011 ACM SIGCOMM Conference on Internet Measurement Conference, Berlin, Germany, 2-4 November 2011; pp. 361-370.

18. Agostino, D. Using social media to engage citizens: A study of Italian municipalities. Public Relat. Rev. 2013, 39, 232-234.

19. Huesch, M.D.; Galstyan, A.; Ong, M.K.; Doctor, J.N. Using social media, online social networks, and internet search as platforms for public health interventions: A pilot study. Health Serv. Res. 2016, 51, 1273-1290.

20. Panyam, S.; Roby, F.; Mansukhani, S. Social Networking Relevance Index. U.S. Patent No. 8,930,453, 6 June 2015.

21. Cialdini, R.B.; Goldstein, N.J. Social Influence: Compliance and Conformity. Ann. Rev. Psychol. 2004, 55, $562-591$. 
22. Ravindran, T.; YeowKuan, A.C.; Hoe Lian, D.G. Antecedents and effects of social network fatigue. J. Assoc. Inf. Sci. Technol. 2014, 65, 2306-2320.

23. Maier, C.; Laumer, S.; Eckhardt, A.; Weitzel, T. When Social Networking Turns to Social Overload: Explaining the stress, Emotional Exhaustion, and Quitting Behavior from Social Network sites' Users. Ecis 2014, 71, 127-150.

24. Turel, O.; He, Q.; Xue, G.; Xiao, L.; Bechara, A. Examination of neural systems sub-serving Facebook “addiction". Psychol. Rep. 2014, 115, 675-695.

25. Lim, X.J.; Radzol, A.M.; Cheah, J.; Wong, M.W. The impact of social media influencers on purchase intention and the mediation effect of customer attitude. Asian J. Bus. Res. 2017, 7, 19-36.

26. Lui, Q.; Zhu, S.P.; Zhou, J.; Yu, Z.Y. Fatigue reliability assessment of turbine discs under multi-source uncertainties. Fatigue Fract. Eng. Mater. Struct. 2018, 41, 1291-1305.

27. Mao, H.; Bao, T.; Shen, X.; Li, Q.; Seluzicki, C.; Im, E.O.; Mao, J.J. Prevalence and risk factors for fatigue among breast cancer survivors on aromatase inhibitors. Eur. J. Cancer 2018, 101, 47-54. [CrossRef] [PubMed]

28. Shen, X.L.; Cheung, C.M.; Lee, M.K. Perceived critical mass and collective intention in social media-supported group communication. Int. J. Inf. Manag. 2017, 33, 707-715. [CrossRef]

29. Strober, L.B.; DeLuca, J.O.H.N. Fatigue: Its influence on cognition and assessment. Second. Influ. Neuropsychol. Test Perform. 2013, 19, 117-141.

30. Tang, L.; Liu, H. Learning with Large-Scale Social Media Networks. Ph.D. Thesis, Arizona State University, Tempe, AZ, USA, July 2010.

31. Guest Post. Facebook is Facing User Fatigue. Hyperbot. Available online: http://www.hypebot.com/hypebot/ 02/facebook-facing-user-fatigue.html (accessed on 12 December 2019).

32. Dwivedi, Y.K.; Kelly, G.; Janssen, M.; Rana, N.P.; Slade, E.L.; Clement, M. Social Media: The good, the bad, and the ugly. Inf. Syst. Front. 2018, 20, 419-423. [CrossRef]

33. Karahanna, E.; Xu, S.X.; Zhang, N. Psychological ownership motivation and use of social media. J. Mark. Theory Pract. 2015, 23, 185-207.

34. Ragu-Nathan, T.S.; Tarafdar, M.; Ragu-Nathan, B.S.; Tu, Q. The consequences of technostress for end users in organizations: Conceptual development and empirical validation. Inf. Syst. Res. 2008, 19, 417-433. [CrossRef]

35. Lee, A.R.; Son, S.M.; Kim, K.K. Information and communication technology overload and social networking service fatigue: A stress perspective. Comput. Hum. Behav. 2016, 55, 51-61. [CrossRef]

36. Tarafdar, M.; Tu, Q.; Ragu-Nathan, B.S.; Ragu-Nathan, T.S. The impact of technostress on role stress and productivity. J. Manag. Inf. Syst. 2007, 24, 301-328. [CrossRef]

37. Yao, J.; Cao, X. The balancing mechanism of social networking overuse and rational usage. Comput. Hum. Behav. 2017, 75, 415-422. [CrossRef]

38. Karr Wisniewski, P.; Lu, Y. When more is too much: Operationalizing technology overload and exploring its impact on knowledge worker productivity. Comput. Hum. Behav. 2010, 26, 1061-1072. [CrossRef]

39. Gan, C. An empirical analysis of factors influencing continuance intention of mobile instant messaging in China. Inf. Develop. 2015, 32. [CrossRef]

40. Zhang, S.; Zhao, L.; Lu, Y.; Yang, J. Do you get tired of socializing? An empirical explanation of discontinuous usage behavior in social network services. Inf. Manag. 2016, 53, 904-914. [CrossRef]

41. Gao, Y.; Wang, S.; Padmanabhan, A.; Yin, J.; Cao, G. Mapping spatiotemporal patterns of events using social media: A case study of influenza trends. Int. J. Geogr. Inf. Sci. 2018, 32, 425-449. [CrossRef]

42. Mazer, J.P.; Murphy, R.E.; Simonds, C.J. I'll see you on Facebook: The Effects of Computer-Mediated Teacher Self-Disclosure on student Motivation, Affective Learning, and Classroom Climate. Commun. Educ. 2007, 56, 1-17. [CrossRef]

43. Smith, A. Why Americans Use Social Media: Social Networking Sites are Appealing as a Way to Maintain Contact with Close Ties and Reconnect with Old Friends. Pew Internet \& American Life Project. Available online: https://www.pewresearch.org/internet/2011/11/15/why-americans-use-social-media/ (accessed on 12 December 2019).

44. Casale, S.; Rugai, L.; Fioravanti, G. Exploring the role of positive metacognitions in explaining the association between the fear of missing out and social media addiction. Addict. Behav. 2018, 85, 83-87. [CrossRef]

45. James, T.L.; Lowry, P.B.; Wallace, L.; Warkentin, M. The effect of belongingness on obsessive-compulsive disorder in the use of online social networks. J. Manag. Inf. Syst. 2017, 34, 560-596. [CrossRef] 
46. Leung, X.Y.; Bai, B. How motivation, opportunity, and ability impact travelers' social media involvement and revisit intention. J. Travel Tour. Mark. 2013, 30, 58-77. [CrossRef]

47. Putrevu, S. Consumer responses toward sexual and nonsexual appeals: The influence of involvement, need for cognition (NFC), and gender. J. Advert. 2008, 37, 57-70. [CrossRef]

48. Prasad, S.; Gupta, I.C.; Totala, N.K. Social media usage, electronic word of mouth and purchase-decision involvement. Asia-Pac. J. Bus. Adm. 2017, 9, 134-145. [CrossRef]

49. Linda, H. Exploring customer brand engagement: Definition and themes. J. Strateg. Mark. 2011, 19, 555-573.

50. Khan, I.; Dongping, H.; Wahab, A. Does culture matter in effectiveness of social media marketing strategy? An investigation of brand fan pages. Aslib J. Inf. Manag. 2016, 68, 697-715. [CrossRef]

51. Zhu, Y.; Bao, Z. The role of negative network externalities in SNS fatigue: An empirical study based on impression management concern, privacy concern, and social overload. Data Technol. Appl. 2018, 52, 313-328. [CrossRef]

52. Zhao, L.; Lu, Y.; Gupta, S. Disclosure intention of location-related information in location-based social network services. Int. J. Electron. Commer. 2012, 16, 53-90. [CrossRef]

53. Shin, D.H. The effects of trust, security and privacy in social networking: A security-based approach to understand the pattern of adoption. Interact. Comput. 2010, 22, 428-438. [CrossRef]

54. Shin, J.; Shin, M. To be connected or not to be connected? Mobile messenger overload, fatigue, and mobile shunning. Cyberpsychol. Behav. Soc. Netw. 2016, 19, 579-586. [CrossRef]

55. Misra, S.; Stokols, D. Psychological and health outcomes of perceived information overload. Environ. Behav. 2012, 44, 737-759. [CrossRef]

56. Ayyagari, R.; Grover, V.; Purvis, R. Technostress: Technological antecedents and implications. MIS Q. 2011, 35, 831-858. [CrossRef]

57. Li-Barber, K.T. Self-disclosure and student satisfaction with Facebook. Comput. Hum. Behav. 2012, 28, 624-630.

58. McCloskey, D.W. The importance of ease of use, usefulness, and trust to online consumers: An examination of the technology acceptance model with older customers. J. Organ. End User Comput. (JOEUC) 2006, 18, 47-65. [CrossRef]

59. Li, M.; Wang, L.; Wu, M. An integrated methodology for robustness analysis in feature fatigue problem. Int. J. Prod. Res. 2014, 52, 5985-5996. [CrossRef]

60. Maire, C.; Laumer, S.; Eckhardt A and Weitzel, T. Online social networks as a source and symbol of stress: An empirical analysis. In Proceedings of the 33rd International Conference on Information Systems, Orlando, FL, USA, 16-19 December 2012.

61. Animesh, A.; Pinsonneault, A.; Yang, S.B.; Oh, W. An odyssey into virtual worlds: Exploring the impacts of technological and spatial environments on intention to purchase virtual products. MIS Q. 2011, 35, 789-810. [CrossRef]

62. Posey, C.; Lowry, P.B.; Roberts, T.L.; Ellis, T.S. Proposing the online community self-disclosure model: The case of working professionals in France and the U.K.-Who uses online communities. Eur. J. Inf. Syst. 2010, 19, 181-195. [CrossRef]

63. Wilson, R.E.; Gosling, S.D.; Graham, L.T. A review of Facebook research in the social sciences. Perspect. Psychol. Sci. 2012, 7, 203-220. [PubMed]

64. Kankanhalli, A.; Tan, B.C.; Wei, K.K. Contributing knowledge to electronic knowledge repositories: An empirical investigation. MIS Q. 2005, 29, 113-143. [CrossRef]

65. Utz, M.; Tanis, I. VermeulenIt is all about being popular. The effects of need for popularity on social network site use. Cyberpsychol. Behav. Soc. Netw. 2012, 15, 37-42. [CrossRef]

66. Hollenbaugh, E.; Ferris, A. Facebook self-disclosure: Examining the role of traits, social cohesion, and motives. Comput. Hum. Behav. 2014, 20, 50-58. [CrossRef]

67. Przybylski, A.K.; Murayama, K.; DeHaan, C.R.; Gladwell, V. Motivational, emotional, and behavioral correlates of fear of missing out. Comput. Hum. Behav. 2013, 1841-1848. [CrossRef]

68. Osemeahon, O.S.; Agoyi, M. Linking FOMO and smartphone use to social media brand communities. Sustainability 2020, 12, 2166. [CrossRef]

69. Argan, M. Fomsumerism: A Theoretical Framework. Int. J. Mark. Stud. 2018, 10, 109. [CrossRef]

70. Kardefelt-Winther, D. A conceptual and methodological critique of internet addiction research: Towards a model of compensatory internet use. Comput. Hum. Behav. 2014, 31, 351-354. [CrossRef] 
71. Oberst, U.; Elisa, W.; Benjamin, S.; Matthias, B.; Abdres, C. Negative consequences from heavy social networking in adolescents: The mediating role of fear of missing out. J. Adolesc. 2017, 55, 51-60. [CrossRef] [PubMed]

72. Maier, C.; Laumer, S.; Eckhardt, A.; Weitzel, T. Giving too much social support: Social overload on social networking sites. Eur. J. Inf. Syst. 2015, 24, 447-464. [CrossRef]

73. Podsakoff, N.P.; LePine, J.A.; LePine, M.A. Differential challenge stressor-hindrance stressor relationships with job attitudes, turnover intentions, turnover, and withdrawal behavior: A meta-analysis. J. Appl. Psychol. 2007, 92, 438. [CrossRef]

74. Błachnio, A.; Przepiórka, A. Facebook intrusion, fear of missing out, narcissism, and life satisfaction: A cross-sectional study. Psychiatry Res. 2018, 259, 514-519. [CrossRef]

75. Chaouali, W. Once a user, always a user: Enablers and inhibitors of continuance intention of mobile social networking sites. Telemat. Inform. 2016, 33, 1022-1033. [CrossRef]

76. Chen, R. Living a private life in public social networks: An exploration of member self-disclosure. Decis. Support Syst. 2013, 55, 661-668. [CrossRef]

77. Bright, L.F.; Kleiser, S.B.; Grau, S.L. Too much Facebook? An exploratory examination of social media fatigue. Comput. Hum. Behav. 2015, 44, 148-155. [CrossRef]

78. Chang, I.; Liu, C.C.; Chen, K. The Push, Pull and Mooring Effects in Virtual migration for Social Networking Sites. Inf. Syst. J. 2014, 24, 323-346. [CrossRef]

79. Shiue, Y.C.; Chiu, C.M.; Chang, C.C. Exploring and mitigating social loafing in online communities. Comput. Hum. Behav. 2010, 26, 768-777. [CrossRef]

80. Barclay, D.; Thompson, R.; Higgins, C. The partial least squares (PLS) approach to causal modelling: Personal computer adoption and use as an illustration. Technol. Stud. 1995, 2, 285-309.

81. Aiken, L.S.; West, S.G.; Reno, R.R. Multiple Regression: Testing and Interpreting Interactions; Sage: Newbury Park, CA, USA, 1991.

82. Beyens, I.E.; Frison, S. Eggermont. "I don't want to miss a thing": Adolescents' fear of missing out and its relationship to adolescents' social needs, Facebook use, and Facebook related stress. Comput. Hum. Behav. 2016, 64, 1-8. [CrossRef]

83. Georgieva, E.S.; Danilova, Y.S.; Bykov, A.Y.; Sergeevna, A.S.; Labush, N.S. Media systems of South-Eastern Europe in the condition of democratic transition: The example of Albania, Bulgaria, Macedonia and Serbia. Int. Rev. Manag. Mark. 2015, 6, 105-114.

84. Seko, Y.; Lewis, S.P. The self-Harmed, visualized, and reblogged: Remaking of self-injury narratives on Tumblr. New Media Soc. 2018, 20, 180-198. [CrossRef]

85. Fondevila-Gascón, J.F.; Polo-López, M.; Rom-Rodríguez, J.; Mir-Bernal, P. Social media Influence on consumer behavior: The case of mobile telephony manufacturers. Sustainability 2020, 12, 1506. [CrossRef]

86. Zimaitis, I.; Degutis, M.; Urbonavicius, S. Social media use and paranoid. Factors that matter in online shopping. Sustainability 2020, 12, 904. [CrossRef]

87. Technopedia. Definition of Social Media Fatigue. 2011. Available online: https://www.techopedia.com/ definition/27372/social-media-fatigue (accessed on 12 December 2019).

(C) 2020 by the authors. Licensee MDPI, Basel, Switzerland. This article is an open access article distributed under the terms and conditions of the Creative Commons Attribution (CC BY) license (http://creativecommons.org/licenses/by/4.0/). 